\title{
EL SEGURO DE DESGRAVAMEN HIPOTECARIO: ASPECTOS ESENCIALES Y FUNCIÓN SOCIAL
}

\section{THE INSURANCE OF MORTGAGE DEBT: ESSENTIAL ASPECTS AND SOCIAL FUNCTION}

\author{
NORA ANDREINA CLAROS SORIA* \\ Fecha de recepción: 22 de abril de 2019 \\ Fecha de aceptación 30 junio de 2019 \\ Disponible en línea: 30 de Julio de 2019
}

Para citar este artículo/To cite this article

Claros Soria, Nora Andreina, El seguro de desgravamen hipotecario: aspectos esenciales y función social, 50 Rev.IberoLatinoam.Seguros, 119-148 (2019). https://doi.org/10.11144/Javeriana.ris50.sdha

doi:10.11144/Javeriana.ris50.sdha

* Profesional en Derecho, Licenciada por la Universidad Católica Boliviana - San Pablo, Maestría en Seguros y Gerencia de Riesgo (Fundación Mapfre- Universidad de Salamanca), Especialista en Derecho de Seguros en la Universidad de Salamanca - España; ha cursado una serie de postgrados entre los cuales destacan: Arbitraje Interno e Internacional (CAINCO - Universidad Católica Boliviana - San Pablo), Derecho Procesal y Oralidad (Universidad de Valle), Riesgos, Seguros y Reaseguros (Fundación Idea - Universidad Católica Boliviana) y Directrices Gerenciales (Univesity of California Irving - ADEN International Business School) entre otros; es miembro activo de ICC Bolivia - Comisión Arbitraje Comercial y Prácticas Legales y Comerciales. Desde hace 10 años se desempeña como Gerente Nacional Corporativa de Asesoría Legal del Grupo Asegurador Alianza en Bolivia. Contacto: noracs@alianzaseguros.com 


\section{RESUMEN}

La aparición de los seguros lleva implícita una función social traducida en la transferencia del riesgo a una entidad especializada, para que, ante una eventual afectación al patrimonio, a la integridad, a la salud o a la vida de una persona, se pueda otorgar al contratante o asegurado o a quien, revista la calidad de beneficiario, la prestación convenida. De esta forma el asegurado no deberá asumir con su propio patrimonio, los daños o el costo implicados en la ocurrencia del riesgo.

Muchos asegurados y en si los directos afectados, al contratar un Seguro de Desgravamen Hipotecario no prestan verdadera atención, ni otorgan la debida importancia a esta modalidad de seguro, que no tiene otra finalidad más que la protección del beneficiario real de la cobertura que otorga el seguro. El beneficiario debe ser entendido no como la entidad financiera que genera la fuente de repago del crédito otorgado, sino como la familia, que indistintamente de perder o ver disminuido en sus capacidades, a quien fungía como cabeza del ingreso económico del hogar, pueda quedarse tranquila y con el bien hipotecado liberado, frente al deceso ocurrido o la incapacidad presentada, en el titular del crédito.

Palabras clave: Beneficiario; Desgravamen; Hipotecario; Protección; Riesgo; Transferencia. 


\begin{abstract}
The emergence of insurance carries implicitly a social function translated into the transfer of risk to a specialized entity, so that, in the event of any impairment to the patrimony, integrity, health or life of a person, it can be granted to the contractor or insured or who, the quality of beneficiary, the benefit agreed. In this way, the insured must not assume with his own patrimony, the damages or the cost involved in

Many insured persons and themselves affected by contracting a Mortgage Relief Insurance do not pay real attention, nor do they give due importance to this type of insurance, which has no other purpose than the protection of the real beneficiary of the coverage granted by the beneficiary. safe. The beneficiary must be understood not as the financial institution that generates the source of repayment of the granted credit, but as the family, who indistinctly lose or see diminished in their abilities, who served as head of the household income, can remain calm and with the mortgaged property released, in the event of the death or incapacity presented, in the holder of the credit.
\end{abstract}

Keywords: Beneficiary; Relief; Mortgage; Protection; Risk; Transfer.

\title{
SUMARIO
}

1. SEGUROS DE PERSONAS - 1.1. Definición - 1.2 Elementos del contrato de seguros de vida - 1.2.1 Asegurador - 1.2.2 Asegurado - 1.2.3. Tomador 1.2.4 Beneficiario - 1.2.4.1 Beneficiario a título gratuito - 1.2.4.2 Beneficiario a título oneroso - 1.3 Clasificación - 1.3.1 Clasificación de acuerdo al riesgo que amparan - 1.3.1.1 seguros de vida - 1.3.1.2 Seguros de accidentes personales - 1.3.1.3. Salud - 1.3.2 Clasificación de acuerdo a la cantidad de asegurados - 1.3.2.1 Seguros individuales - 1.3.2.1.1 Seguro de vida temporal uniforme 1.3.2.1 Seguro de vida temporal decreciente - 1.3.2.1.2.1 Seguro de vida para amortización de hipoteca - 1.3.2.1.2.2 Seguro de crédito o de saldo deudor - 1.3.2.1.2.3 Seguro colectivo de vida acreedor o de saldo deudor - 1.3.2.2 Seguros colectivos - 2. REGULACION DEL CONTRATO DE SEGUROS - 2.1 Carácter proteccionista - 3. SEGURO DE DESGRAVAMEN HIPOTECARIO 3.1 Elementos formales del seguro de desgravamen hipotecario en la legislación boliviana - 3.2 Práctica abusiva: subordinación del seguro de vida al contrato de préstamo de dinero - 3.3 Indemnización en el seguro de desgravamen hipotecario - 4. LEGISLACION COMPARADA - 4.1 España - 4.2 Perú 4.3 Colombia - 4.4 Argentina - 4.5 Uruguay - CONCLUSION - BIBLIOGRAFIA. 



\section{SEGUROS DE PERSONAS}

Fue durante la época de la Antigüedad y la Edad Media que aparecen los primeros sistemas de ayuda mutua que dan lugar al surgimiento de los seguros de vida o de personas como tal.

Durante esta época las diferentes civilizaciones tuvieron aportaciones importantes dentro las cuales destacamos en Babilonia (casi 4.000 años atrás) al "Código de Hamurabi", cuerpo legal que preveía no solo una forma de protección contra la pérdida de mercancías sino también frente a la pérdida de la vida humana, estableciendo que el Estado indemnizaría a las esposas y descendientes en caso de que, por robo, ocurriera la muerte del cónyuge. Fuera de esta figura se instituiría la indemnización por accidentes de trabajo, a través de organizaciones denominadas sociedades mutuas.

De la misma manera Egipto, establecería la ayuda mutua entre socios de una institución, para ayudar en los ritos funerarios del socio que falleciera; y en Roma aparecería lo que conocemos como:"Collegia Tenuiorum, Collegia Funeraticia", constituida por los artesanos, para participar de gastos por muerte, seguridad constituida por un fondo formado por el Estado y por los beneficiarios y herencias dejadas por socios muertos.

A partir del siglo XVII en adelante, se afianzan los fundamentos técnicos y jurídicos del seguro en general y de vida en especial, en 1634 con Blas Pascal (famoso matemático) quien da lugar al nacimiento del Cálculo de las Probabilidades y a la Teoría de los Grandes Números, al igual que surgen en Inglaterra, John Graund (1662) y Edmund Halley (1693) elaborando las primeras Tablas de Mortalidad, bajo fundamentos técnicos mismos que dan origen a la formación y aparición de las primeras empresas de seguros de vida, debido al crecimiento de la Industria.

\subsection{Definición}

El Seguro de Personas, es una de las tres Modalidades de Seguros reconocidas y, permitida en el caso específico de Bolivia; que tiene por objeto

$1 \quad$ Ley de Seguros No. 1883 de 25 de Junio 1998, Art. 5. 
asegurado a toda persona natural, cuya existencia, salud o integridad pueda verse afectada por el acaecimiento de un riesgo.

En este mismo sentido, algunos estudiosos en el ámbito de seguros, entre ellos el Ing. David Bellido² (ex Director de Seguros de la Autoridad de Regulación Boliviana) entiende a los seguros de personas como aquellos riesgos que pueden destruir totalmente o en parte el valor económico de una vida humana, comprendiendo la muerte prematura, perdida de la salud, vejez o desempleo. Si bien el desempleo es un riesgo que afecta a la vida humana y desde el punto de vista técnico debiera formar parte de esta modalidad de seguro de personas, la propia legislación boliviana, limita los riesgos amparados a los descritos en el párrafo precedente, llegando a considerarse por consiguiente a éste como un riesgo de daños.

Bajo esta premisa, al referirnos al valor económico entendemos la idea de que cada persona, de manera libre y voluntaria, podrá otorgar una estimación económica cuantificable a su vida y permanencia sana, basada no solo en la actividad que ejerce y el rol que desempeña en su familia, sino también en distintas premisas utilizadas por las entidades autorizadas para operar en este ramo, que harán que la relación entre asegurado y asegurador, producto de una póliza de seguros de vida, tenga un punto de partida y de equilibrio, en caso de que la eventualidad se produzca.

Indistintamente de lo manifestado y, en lo que refiere al presente trabajo de investigación cabe tener en cuenta que la estimación o cuantificación de la vida de una persona, podría estar directamente relacionada a una obligación contractual de carácter pecuniario, que tendrá como resultado la estimación de un monto determinado en relación directa a un préstamo otorgado por una entidad bancaria o de intermediación financiera.

\subsection{Elementos del contrato de seguros en los seguros de vida}

Resulta, asimismo importante para lograr un cabal entendimiento del tema principal abordado, para esta modalidad de seguros, resaltar los elementos 2 BELLIDO CHAVEZ, D. (2017). El Seguro sus bases técnicas y jurídicas, La Paz - Bolivia. 
personales o subjetivos (como son también conocidos en otras legislaciones) del Contrato de Seguros de manera específica en los Seguros de Vida.

En tal sentido, diremos que constituyen de manera general partes contratantes o elementos subjetivos del Contrato de Seguros de Vida, los siguientes:

1.2.1 Asegurador, refiere a la persona jurídica que asume los riesgos comprendidos en el Contrato, (entidad aseguradora, compañía de seguros, etc.). También se entiende por tal aquella organización cuya razón social en la mayoría de los mercados refiere a la figura jurídica de una Sociedad Anónima, encargadas de proveer los servicios de seguros, bajo la asunción de los mismos a cambio de una contraprestación llamada prima o premio.

1.2.2 Asegurado, referido a la persona titular del interés asegurable que designará a uno o más beneficiarios para que en caso de ocurrir su fallecimiento pasen a ser titulares de los derechos a recibir la suma asegurada o las prestaciones estipuladas.

1.2.3 Tomador, es otro elemento subjetivo importante en los Seguros de Vida entendido como la persona (natural o jurídica) que por cuenta y a nombre de un tercero, contrata con el asegurador la cobertura de riesgos encomendada, inclusive sin el consentimiento del o los asegurados siempre que exista interés asegurable para ello. (Por ejemplo: póliza contratada por el empleador para sus empleados o funcionarios).

1.2.4 Beneficiario, es aquella persona designada por el asegurado o contratante de la póliza, como eventual titular de los derechos emergentes de la póliza en caso de fallecimiento del asegurado, o como bien se diría aquel que goza de la prestación emergente del siniestro. El beneficiario como tal, adquiere un derecho propio y directo sobre el producto del seguro, a recibir la prestación, a partir del momento en que se produce el fallecimiento del asegurado. 
En este sentido, el Beneficiario durante la vida del asegurado tiene un mero interés en la prestación, pues puede ser revocado o cambiado. Esta situación cambia en caso del beneficiario irrevocable u oneroso: el derecho lo tiene desde el inicio y podemos hablar de una real indemnización, pues tiene relación con el monto adeudado.

Para lograr un cabal entendimiento de lo señalado en nuestro marco normativo ${ }^{3}$, podemos decir que son partes del contrato de seguros:

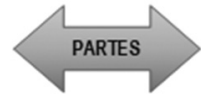

ASEGURADOR

Y constituyen otros elementos personales del contrato de seguros:

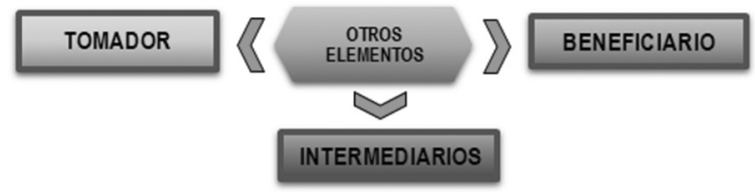

Ilustramos a las partes del contrato de seguros, toda vez, que algunas legislaciones se considera al tomador como la contraparte contractual, al ser quien celebra el contrato con el asegurador; para El Código de Comercio de Bolivia, tanto los intermediarios, como el tomador y beneficiario, constituyen otros elementos de la relación contractual.

Fuera de lo comentado, resulta fundamental tomar en cuenta lo dispuesto por la normativa boliviana ${ }^{4}$, ya que realiza una puntualización en lo que refiere la figura del Beneficiario como otro elemento del contrato de seguros, clasificándolo en función a su designación, en:

1.2.4.1 Beneficiario a título gratuito mismo que estará designado en virtud de un vínculo afectivo o filial o,

1.2.4.2 Beneficiario a título oneroso que se designa en virtud de un vínculo obligacional; por ejemplo, acreedor en seguridad de su crédito; definiéndose como aquel cuya designación

3 Código de Comercio de Bolivia, Decreto Ley Nº 14379 de 15 de febrero de 1977, Arts. 987.

4 IDEM, Art. 1128. 
tenga por causa una obligación contractual del asegurado a favor de aquel. A falta de estipulación se presume que el beneficiario es a título gratuito.

Resulta pues imprescindible que exista total claridad en la designación de los beneficiarios de una Póliza de Seguros de Vida.

La Dra. Andrea Signorino B. sobre el punto, hace mención a la figura del Beneficiario Irrevocable ${ }^{5}$, denominado también a Título Oneroso, manifestando que éste reviste un interés creado en la póliza de Seguro de Vida, refiriéndose al derecho que entraría en vigor al momento de su designación, no pudiendo ser alterado ni modificado sin el consentimiento de la persona a la cual le asiste este derecho ${ }^{6}$. En tal sentido, la entidad aseguradora sin que exista el derecho del beneficiario irrevocable difícilmente podría dejar al asegurado ejercer sus derechos propietarios sobre el contrato.

Esta designación, no responde a la voluntad del asegurado, sino a la existencia de un negocio jurídico u obligación legal que le compete a efectuarla, en consecuencia; para poder proceder con el cambio de designación, debe procurar una autorización por escrito del beneficiario irrevocable u oneroso.

\subsection{Clasificación de los seguros de personas}

Asimismo, resulta apropiado determinar dentro de que clasificación podemos enmarcar al Seguro de Desgravamen Hipotecario, teniendo en cuenta el riesgo que ampara cada sub ramo y la cantidad de asegurados que puede existir en una determinada póliza.

\subsubsection{Clasificación de acuerdo al riesgo que amparan}

Las principales corrientes señalan que los Seguros de Personas se clasifican en tres sub ramos de acuerdo al riesgo que ampara cada uno de ellos, que son:

5 SIGNORINO BARBAT, Andrea. Los Seguros de Vida - Principales aspectos técnicos, jurídicos y comerciales, 2008, Uruguay.

6 LOMA (Life Management Institute Loma) Manual "Principios del Seguro de Vida, Salud y Rentas Vitalicias, Atlanta - Georgia. 
1.3.1.1. Seguros de vida, entendido como aquellos que amparan los riesgos que afectan a la existencia de las personas naturales, dicho de otra manera, cubren el riesgo de muerte natural; considerado un contrato de suma puro, vale decir, que la determinación de la suma asegurada se fija y pacta entre las partes de forma libre y voluntaria.

El Diccionario de Seguros de la Fundación Mapfre, se refiere al Seguro de Vida, como uno de los tipos del seguro de personas, en el que el pago por el asegurador de la cantidad estipulada en el contrato se hace depender del fallecimiento o supervivencia del asegurado en una época determinada; distinguiendo dos modalidades del seguro de vida: a) Seguro en caso de muerte, que es aquel en el que el beneficiario recibirá el capital estipulado cuando se produzca el fallecimiento del asegurado, y; b) Seguro en caso de vida, referido a que el beneficiario percibirá el capital si el asegurado vive en una fecha determinada.

1.3.1.2. Seguros de accidentes, son aquellos que protegen a las personas naturales contra los riesgos que afectan su integridad física, emergentes de hechos fortuitos, súbitos y violentos y que no comprenden los provenientes de enfermedades.

En lo que refiere a este tipo de seguro, el Diccionario de Seguros Mapfre señala que es aquel que tiene por objeto la prestación de indemnizaciones en caso de accidentes que motiven la muerte o incapacidad del asegurado, a consecuencia de actividades previstas en la póliza.

1.3.1.3. Seguros de salud, son entendidos como aquellos que cubren los servicios médicos, quirúrgicos, farmacéuticos y de internación en centros de salud, denominados también como seguros de Asistencia Médica.

A este efecto, el referido Diccionario de Seguros, describe como un Seguro de Salud, a aquel que indemniza (total o parcialmente según la modalidad contratada), o presta el servicio profesional 
de la medicina, en caso de enfermedad ambulatoria, hospitalaria, o en el supuesto de maternidad, así como los exámenes médicos necesarios para el asegurado a consecuencia de enfermedad o accidente.

\subsubsection{Clasificación de acuerdo a la cantidad de asegurados}

Los seguros de manera general pueden, indistintamente de la naturaleza del riesgo que amparan, ser clasificados de acuerdo a la cantidad de asegurados que amparan las pólizas, resultando dos tipos de seguros:

1.3.2.1. Seguros individuales; dentro del cual la figura de tomador y asegurado del seguro, refieren una misma persona, ya sea natural o jurídica.

La Dra. Andrea Signorino ${ }^{\mathbb{Z}}$ manifiesta con relación a los Seguros Individuales que éstos a su vez, pueden ser: Seguros de vida puros, denominados también Temporarios de vida o seguros de vida temporal; cuyas modalidades refieren de acuerdo a la constancia o no del beneficio:

1.3.2.1.1. Seguro de vida temporal uniforme, donde el capital asegurado permanece constante durante la vigencia de la póliza, al igual que el monto de la prima de renovación.

\subsection{Seguro de vida temporal decreciente,} donde el capital asegurado disminuye a lo largo del plazo de la cobertura de acuerdo al método estipulado en la póliza y el monto de la prima de renovación se mantiene en general, uniforme.

Dentro de los productos que refieren los Seguros de Vida Temporal Decreciente tenemos:

\subsection{Seguros de vida para amortización}

de hipoteca, referido al plan pensado para proporcionar un monto de capital por muerte que corresponde al monto decreciente

$7 \quad$ SIGNORINO BARBAT, A. Los Seguros de Vida - Principales aspectos técnicos, jurídicos y comerciales, 2008, Uruguay. 
adeudado sobre una hipoteca, siempre que se trate de pagos que refieran a capital e intereses.

El beneficiario utiliza la indemnización en caso de fallecimiento del deudor (asegurado) para pagar la hipoteca pero no necesariamente debe ser así, ya que la institución que otorga la hipoteca no es parte del Contrato de Seguros.

\subsection{Seguros de crédito o de saldo deu-} $\boldsymbol{d o r}$, son aquellos diseñados para pagar el saldo adeudado de un préstamo si el deudor fallece antes de amortizar totalmente el mismo. Aunque este seguro se comercializa de forma individual, la mayoría de ellos se venden a las instituciones prestadoras como seguros colectivos para cubrir las vidas de los prestatarios de dicho acreedor; garantizando por un lado al acreedor el pago de la deuda del asegurado frente a su deceso y por otro, protegiendo a los herederos del asegurado de tener que pagar las deudas de éste.

La principal diferencia con los de amortización de Hipoteca es que siempre disponen que el beneficio o indemnización será pagadera directamente al prestador o acreedor si el deudor muere durante la vigencia de la póliza.

\subsection{Seguro colectivo de vida acreedor 0} de saldo deudor, que es emitido por el acreedor, para asegurar la vida de sus actuales y futuros deudores; siendo el acreedor y contratante el beneficiario para el caso de muerte del deudor. Por lo general, la prima de este seguro es pagada por el deudor, aunque puede estar a cargo del acreedor o bien ser compartida.

1.3.2.2. Seguros colectivos; denominados también seguros en grupo, refieren la forma de otorgar cobertura de seguro a un grupo de personas homogéneas, en un solo y único contrato o póliza. Respecto a las pólizas individuales, la característica de este seguro radica principalmente en que el tomador y asegurado son personas diferentes. 
La normativa boliviana define a los Seguros Colectivos de la siguiente manera: "Aquellos caracterizados por cubrir mediante un solo contrato o póliza de seguro, suscrito entre el tomador y la entidad aseguradora, a múltiples asegurados, cuyas coberturas están referidas a personas y objetos dentro de las modalidades de Seguros Generales y/o Seguros de Personas".

\section{REGULACION DEL CONTRATO DE SEGUROS}

\subsection{Carácter proteccionista}

Por norma general, las distintas legislaciones en materia de seguros, determinan la existencia del principio de equidad e igualdad en las relaciones entre asegurados, tomadores y beneficiarios de seguros y las Entidades Aseguradoras, a través de la regulación del Contrato de Seguro y de los entes llamados a fiscalizar la actividad aseguradora.

Bolivia no se encuentra al margen de esta situación y es a través de la Autoridad de Fiscalización y Control de Pensiones y Seguros, entidad supervisora y fiscalizadora de la actividad aseguradora nacional; que establece el carácter proteccionista que reviste en favor de los asegurados de manera general, bajo indicadores normativos. Por ejemplo, así lo hace la Ley de Seguros en su artículo 1883, entre otras disposiciones en el mismo sentido.

"La protección jurídica a los asegurados, tomadores y beneficiarios del seguro, se concretará en los siguientes aspectos:

a.- La oferta de productos y servicios se ajustará a la naturaleza, condiciones, precio y modalidades que se publiciten, ya sean en las dependencias de la entidad aseguradora o a través de anuncios, prospectos, circulares o cualquier medio de comunicación.

$8 \quad$ Resolución Administrativa Nº 172/2001 - ex Superintendencia de Pensiones, Valores y Seguros, La Paz - Bolivia. 
b.- El alcance del contrato de seguros, en caso de discrepancia, ambigüedad o duda será interpretado siempre del modo más favorable para el asegurado, tomador o beneficiario.

c.- Las cláusulas que subordinen la efectividad del pago o del servicio a la aceptación de otras prestaciones o servicios suplementarios por la misma u otra entidad aseguradora, son ineficaces. "”

Bajo este entendido, podemos inferir que esta atribución de reglamentar la Actividad Aseguradora atribuida al ente supervisor del Mercado de Seguros y Pensiones (APS), ligada a la atribución de resguardar y delimitar los productos desarrollados en Banca-Seguros, reconocida al ente que supervisa el Sistema Financiero (ASFI); dan lugar a la aparición y reglamentación del Seguro de Desgravamen Hipotecario para llevar adelante su obligatoria contratación.

\section{SEGURO DE DESGRAVAMEN HIPOTECARIO}

Este tipo de Seguros, conocido también como Seguro Prestamista en el derecho brasilero ${ }^{10}$, se define como aquel que objetivamente garantiza, en caso de muerte o invalidez del asegurado, el cumplimiento de la obligación que éste tiene con el beneficiario. Está catalogado como un seguro utilizado por las instituciones financieras en las operaciones de crédito de consumo y de vivienda, constituyendo un instrumento de garantía para estas operaciones, disminuyendo el riesgo de recuperación del crédito para la entidad bancaria o financiera. $\frac{11}{1}$

En Bolivia, el Seguro de Desgravamen Hipotecario, refiere un Seguro Colectivo que tiene por objeto cubrir a través de la contratación de una póliza, suscrita entre un Tomador/ Beneficiario y la EntidadAseguradora a múltiples asegurados, garantizando el pago de la deuda contraída (saldo insoluto de $9 \quad$ Ley de Seguros No. 1883 de 25 de Junio 1998, Art. 38.

10 CAMPOY, A.J. 2014. Contrato de Seguro de Vida.

11 Circular SUSEP No 302, de 19 de septiembre de 2005 - Superintendencia de Seguros Privados. 
la deuda) con la Institución de Intermediación Financiera (banco) en caso de fallecimiento o invalidez total y permanente del Asegurado (prestatario).

La contratación de este seguro, comercializado por las Entidades Aseguradoras de Seguros de Personas, surge de una obligación de carácter normativo, tras la aprobación del Reglamento del Seguro de Desgravamen Hipotecario de Vivienda y Automotores ${ }^{12}$, concordante con lo dispuesto por el Reglamento para Entidades de Intermediación Financiera, bancos, en su Capítulo III, que actúan como Tomadores de Seguros Colectivos.

Dicho Reglamento tiene por objeto principal, establecer las obligaciones y responsabilidades de las partes, ejerciendo el rol proteccionista, mencionado en el punto 2.1 precedente, a través de dos órganos de Regulación específicos: la Autoridad de Fiscalización y Control de Pensiones y Seguros - APS (para los actores del mercado asegurador) y la Autoridad de Supervisión del Sistema Financiero - ASFI (para los actores del mercado financiero).

Existen, sin embargo, legislaciones como la española ${ }^{\frac{13}{3}}$ en las cuales se considera que la comercialización de préstamos hipotecarios, al no gozar de ese carácter de obligatoriedad, en teoría aunque si con la incorporación de esta exigencia en el condicionado general de las pólizas, refieren a seguros de tipo atípicos. Se señala que estos seguros vulneran derechos de los prestatarios o deudores asegurados, pues exigen suscribir pólizas de seguro de amortización de préstamos como una condición sine qua non para otorgar el préstamo, bajo la modalidad de un seguro de vida. Esto con el compromiso de que, en caso de fallecimiento o incapacidad total y permanente del asegurado, la entidad aseguradora indemnice además del seguro de vida, los importes o saldos pendientes de amortización producto del préstamo concedido.

De manera particular, considero que existe una distorsión en la aplicación del Seguro de Amortización de Prestamos o Desgravamen Hipotecario, toda vez que el importe a indemnizarse refiere justamente el 12 Resolución Administrativa No. 687-2016 de 31 de mayo de 2016 - Autoridad de Fiscalización y Control Social de Pensiones y Seguros - APS.

13 BRENES CORTES, J. 2017. Algunas cuestiones problemáticas derivadas de la concertación de seguros de vida vinculados a préstamos hipotecarios. Especial referencia al cumplimiento del deber de declaración de riesgo. 
saldo pendiente de pago ante la entidad crediticia, ligada a la figura de la existencia de un Seguro de Vida que no se activa de manera separada sino más bien conjunta.

La bibliografía analizada ${ }^{14}$ sobre este tema específico señala en más de una ocasión, un concepto de superioridad que podría entenderse como un flagrante desequilibrio en perjuicio del asegurado o prestatario, vulnerando el principio básico del seguro como lo es la buena fe, entre partes.

Indistintamente de lo mencionado, y bajo un enfoque de cumplimiento de la función social de esta clase de seguros, se entiende que ésta cancelación o indemnización proveniente de la activación de cobertura del Seguro de Desgravamen Hipotecario o Amortización de Préstamos como se conoce en la legislación española, implicaría la liberación de responsabilidad para los llamados a suceder al asegurado y consecuentemente la liberación del bien hipotecario que garantizaba la operación crediticia, situación que definitivamente genera un estado de total tranquilidad para la familia.

Lastimosamente, esta situación deja de tener la plusvalía señalada, cuando se evidencia la tendencia a considerar que se trata de una práctica abusiva y desmedida en contra de los asegurados, sobre todo en España. Esto refiere a que, al ser parte de un grupo empresarial tanto la entidad financiera o crediticia como la entidad aseguradora, en muchos casos prefieren desde toda óptica, no reclamar el pago indemnizatorio del Seguro de Amortización de Préstamos o Desgravamen Hipotecario o bien aceptar el rechazo constituido sobre el mismo sin realizar ninguna gestión extraordinaria, ni mucho menos verificar si el rechazo se encontraría debidamente fundamentado, ejecutando las garantías constituidas al momento de generarse el vínculo obligacional entre las partes, en virtud del contrato de préstamo; ya que, de efectivizarse el pago respectivo, podría esta situación generar una mala exposición contable para las empresas vinculadas.

Distinta seria la percepción, si se le proporcionara al asegurado/ prestatario la posibilidad de escoger si contrata o no este seguro y de 14 BATALLER GRAU, J y PEÑAS MOYANO, M.; 2017. Un derecho del seguro más social y transparente. 
hacerlo, con qué entidad aseguradora desea realizar el contrato, toda vez que, de no cumplirse esta situación, se estaría sobre garantizando la obligación contraída..$\underline{15}$

Resulta pues importante mencionar, que muchas de estas percepciones que refieren una práctica abusiva por parte de las entidades crediticias, podría evitarse si existieran parámetros de determinaran la aprobación de los textos de las condiciones generales, anexos y cláusulas de manera general, como sucede en otros países; situación empero, que no acompañaría y tornaría complejo el crecimiento del mercado español.

Si nos circunscribimos al caso boliviano, podremos evidenciar que indistintamente de que surjan en algún momento este tipo de interrogantes relacionadas a la contratación del Seguro de Desgravamen Hipotecario, nuestra legislación prevé una serie de situaciones que de alguna manera evitan, a través de un proceso de licitación pública, que la contratación obligatoria por mandato de la ley se concentre en ciertos determinados grupos empresariales.

Es por ello que a continuación procederemos a enfatizar las principales características del Seguro de Desgravamen Hipotecario, desde el punto de vista de la legislación boliviana, así como los matices que otras legislaciones pueden otorgarle.

\subsection{Elementos formales del seguro de desgravamen hipotecario en la legislación boliviana}

El primer elemento que se genera al momento de la contratación de un crédito ante una entidad financiera es el Formulario de Solicitud y Declaración de Salud, documento que debe necesariamente ser completado por el asegurado, al revestir el carácter de una declaración jurada sobre su estado actual de salud.

En muchas ocasiones, las entidades aseguradoras, amparadas en este Formulario de Solicitud y Declaración de Salud, rechazan la solicitud de pago

15 BRENES CORTES, J. 2017. Algunas cuestiones problemáticas derivadas de la concertación de seguros de vida vinculados a préstamos hipotecarios. Especial referencia al cumplimiento del deber de declaración de riesgo. 
de un asegurado o del banco, al evidenciarse que los datos contemplados en el mismo carecen de veracidad, al existir enfermedades preexistentes no declaradas, manifestando que habría existido reticencia por parte del asegurado en declarar fehacientemente la información requerida. No obstante, averiguados los antecedentes, se evidencia que el personal de la entidad financiera, confundiendo lo que se entendería como una buena atención al cliente prestatario, proceden a completar los formularios, por agilizar la carpeta del préstamo que debe entrar a un proceso de aprobación, con lo cual la reticencia resulta de dudoso fundamento o no resulta de mala fe.

Indistintamente de las capacitaciones que puedan darse y efectuarse a los funcionarios de las entidades aseguradoras, de las entidades financieras o de intermediación financiera, así como a los corredores, esta situación se está tornando en un verdadero problema que pone en tela de juicio la aplicabilidad de ese carácter de función social que conlleva especialmente este seguro.

La idea de contar con una Póliza de Desgravamen Hipotecario que aglutina a una serie de prestatarios de una cartera conlleva en si la entrega de un Certificado de Cobertura Individual, instrumento documental o mecanismo electrónico mediante el cual un asegurado conocerá el alcance del contrato y sobre todo el procedimiento que deberá activar ya sea él o su familia en caso de producirse el siniestro. Bajo nuestra legislación, se considera obligación de la entidad aseguradora proporcionar este Certificado de Cobertura Individual, para que el personal de la entidad crediticia entregue una copia al asegurado.

Ahora bien, si nos referimos al objeto del Seguro de Desgravamen, entendemos que este se traduce en recuperar la totalidad del Saldo Insoluto de la Deuda contraída a través del contrato de préstamo, es decir, el monto total de la deuda menos las amortizaciones de capital efectuadas más los intereses devengados por el asegurado, prestatario, en caso de producirse las eventualidades de fallecimiento o invalidez total y permanente del mismo. De esto se infiere que estas dos últimas resultarían las coberturas principales.

No obstante, lo mencionado en el caso específico boliviano, la normativa prevé que esta clase de Seguros puede generar o contar con cober- 
turas adicionales tales como gastos de sepelio y/o indemnización de capital adicional de un monto de dinero en efectivo; bajo la condición de que se encuentren debidamente convenidas entre las partes.

\section{La aparición de un Registro de Asegurados del Seguro de Desgra-} vamen Hipotecario, base de datos electrónica que consiga información de cada uno de los asegurados como medio de certificación de la cobertura individual, salta como una idea de avanzada tecnología. Gracias a este Registro todo asegurado a través del sitio web de la entidad aseguradora podrá conocer los términos y condiciones de la póliza contratada, y está directamente ligado a la vigencia de la póliza. Respecto a esta, la normativa refiere a tres (3) años calendario, cuyo cómputo inicia el momento del desembolso del préstamo y finalizará en el momento de la extinción de la operación del préstamo, interrumpiéndose en caso de incumplimiento del pago de prima correspondiente, treinta (30) días después de la fecha de vencimiento de pago (periodo de gracia), periodo durante el cual, indistintamente del incumplimiento de pago de prima, la póliza contaría con cobertura.

En el caso específico del Seguro de Desgravamen Hipotecario se entiende que la prima deberá ser pagada de manera mensual y a mes vencido.

Un punto muy importante, a resaltar como obligación inherente a la Entidad de Intermediación Financiera, que actúe como Tomador del Seguro, refiere el pago oportunamente de la prima individual del seguro colectivo por cuenta del cliente mientras dure la relación contractual $\frac{16}{}$. En caso de que, se realice de manera posterior, no podrá generar para el asegurado contingencia o perjuicio alguno, siendo responsabilidad de la entidad financiera esta situación, lo cual es concordante con lo dispuesto en el Reglamento de Desgravamen Hipotecario.

Finalmente, y no por ello menos importante, debemos señalar que la misma norma establece que una vez producido el siniestro y cumplidos los requisitos mencionados en la póliza, la entidad aseguradora tiene quince (15) días calendario para poder hacer efectiva la indemnización,

16 Reglamento para Entidades de Intermediación Financiera (bancos) que actúan como Tomadores de Seguros Colectivos, Sección 2, Art. 4 inc. d. 
procediendo con el pago de acuerdo a la liquidación proporcionada por la entidad financiera o de intermediación financiera, calculada a la fecha de fallecimiento del asegurado-prestatario.

"En caso de no proceder dentro del plazo, el Código de Comercio aplicable también a la materia, reconoce el pago de intereses."

\subsection{Práctica abusiva: subordinación del seguro de vida al contrato de préstamo de dinero}

En el derecho español, algunos tratadistas $\frac{17}{7}$ manifiestan que la subordinación que se practica respecto de la póliza del seguro de vida al contrato de préstamo de dinero refiere una práctica por demás abusiva para el asegurado, quien no entra en igualdad de condiciones ni con la entidad crediticia, mucho menos con la entidad aseguradora, menos aún si ambas pertenecen a un mismo grupo empresarial.

En este sentido, es necesario precisar que, no obstante el Contrato de Seguro de manera general y por lógica el Seguro de Vida dentro del cual tenemos la figura del Desgravamen Hipotecario, son, en la generalidad de los casos, salvo los seguros de grandes riesgos, contratos de adhesión, frente al cual el asegurado no puede hacer nada más que aceptar las condiciones pre establecidas sin derecho a cuestionarlas, no es menos cierto que en más de una legislación se prevé un plazo prudencial para que el asegurado pueda cuestionar o reclamar a la aseguradora las diferencias entre las condiciones acordadas en su solicitud seguro aceptada y las no plasmadas o contempladas, en el documento del contrato de seguros, póliza, entregado por el asegurador.

Sin ir muy lejos, el caso boliviano establece esta posibilidad que caduca de no ser utilizada por el asegurado o su corredor de seguros en el plazo de quince (15) días posteriores a la entrega de la póliza.

Frente a ello, se señala que, a pesar de esta disposición que pretende aminorar la brecha existente en la relación entidad aseguradora - ase-

17 BRENES CORTES, J. 2017. Algunas cuestiones problemáticas derivadas de la concertación de seguros de vida vinculados a préstamos hipotecarios. Especial referencia al cumplimiento del deber de declaración de riesgo. 
gurado, no se puede dejar de considerar que la balanza por lo general se inclina del lado del más fuerte.

En el caso de España, esta corriente crea aún más fuerza, cuando es el propio sector bancario quien recoge en la guía de acceso al Préstamo Hipotecario elaborada por el Banco de España ${ }^{18}$, la práctica habitual de exigir al prestatario contratar un Seguro de Vida. En realidad, la contratación debería ser de carácter absolutamente voluntario y liberal, previo conocimiento de las condiciones o costos que pudiera generar y no así una imposición o condicionamiento para el prestatario. Esta situación genera tal malestar que contraviene de manera clara al propio ordenamiento jurídico español, toda vez que no reviste los requisitos de claridad, transparencia y sencillez requeridos.

En definitiva, se priva al prestatario de elegir y poder comparar en el mercado asegurador, bajo una premisa de libre oferta y demanda, los servicios que puede o no adquirir.

En este entendido, existen pronunciamientos de parte de los Tribunales Españoles, en relación con la mala práctica llevada adelante por las entidades crediticias, los cuales concluyen que esta exigencia de contratación, al margen de la poca efectividad que en la práctica conlleva, al no realizarse el pago indemnizatorio y procesar la ejecución de garantías reales y/o personales sujetos al préstamo hipotecario, genera un enriquecimiento injusto para el grupo empresarial. $\frac{19}{}$

Bajo esta premisa es que dicha corriente ha defendido la figura de contratación abusiva y contraria a derecho y al principio de buena fe. Esto en base al hecho que, aun cuando la contratación de un seguro de vida para la amortización de un crédito determinado se configure como una garantía

18 Versión mayo de 2016 y elaborada por mandato de la Orden EHA/2899/2011, de 28 de Octubre, de Transparencia y Protección del Cliente de Servicios Bancarios - y en la disposición adicional tercera de la Ley 1/2013, de 14 de mayo; decreta su creación y redacción "con la finalidad de que quienes demanden servicios bancarios de préstamo hipotecario dispongan, con carácter previo a la formalización de los mismos, de información adecuada para adoptar sus decisiones de financiación". Así establecen en relación con los créditos vinculados, que: "las entidades de crédito que comercialicen seguros bancarios vinculados a la contratación de otro servicio, financiero o no, deberán informar al cliente, de manera expresa y comprensible, sobre la posibilidad o no de contratar cada servicio de manera independiente y en qué condiciones."

19 SAP de Alicante $\mathrm{N}^{\circ} 215 / 202$ de 30 de abril de 2002 (JUR 2002, 157190) y SAP de Sevilla de 20 de febrero de 2002 (JUR 2002, 49022). 
adicional en favor de la entidad financiera para conseguir la fuente de repago del préstamo otorgado, si no se establece ningún tipo de prioridad permite a la entidad financiera, escoger libremente que garantía ejecutar si se produce el incumplimiento de pago, siendo recomendable, o más aun debiendo ser exigible para las entidades financieras, reclamar, ante la ocurrencia del siniestro, el pago total convenido a la aseguradora y no así a los herederos del fallecido o sus avales.

Existe de igual manera, otra interrogante en relación con la fecha de entrada en vigor o vigencia de la cobertura del seguro de vida, conforme a los parámetros expuestos. En este sentido, ¿se puede entender que la fecha de suscripción del contrato de préstamo, aun cuando la contratación formal del seguro se realice en forma posterior o bien a falta del pago de prima del seguro por parte del prestatario, daría inicio a la vigencia de la póliza de seguro?

El mismo planteamiento se genera, en relación a los exámenes médicos que pudiera solicitar la entidad aseguradora no imputables al asegurado. Esta situación de manera definitiva no ha sido considerada y solamente genera interrogantes, a la fecha no definitivamente resueltas.

Si revisamos un poco el tratamiento que se da en los países latinoamericanos a este tema, podemos observar que la gran mayoría adopta como fecha de inicio de vigencia de la póliza, la fecha del desembolso del crédito, entendiéndose que, hasta la misma, no se tendrían concluidos los procedimientos tanto en la entidad financiera como en la entidad aseguradora.

Desde el punto de vista español, podemos concluir que resulta abusiva la cláusula inserta en los condicionados generales del contrato de préstamo hipotecario que impone la contratación, adicional a las garantías constituidas vinculadas a la operación crediticia, que la entidad financiera exige con carácter obligatorio, al prestatario, cuando resulta claro que esa obligatoriedad no fue impuesta normativamente, siendo este actuar una violación al principio de libertad del asegurado. 
Al respecto, resulta importante mencionar que la Ley de Mediación de Seguros y Reaseguros Privados ${ }^{20}$ española no contempla que dicha práctica de contratación pueda ser exigida por la entidad prestamista sino estimando la posibilidad de hacerlo.

Lo que, si queda claro, a nuestro criterio, es que para todos aquellos países en los cuales no se prevea de manera taxativa y cuyo ordenamiento positivo no señale la obligatoriedad de contratar un seguro que vida, bajo la modalidad que se denomine (amortización de préstamos, desgravamen hipotecario, etc); resulta desmedida y abusiva la práctica que condicione a cualquier prestatario, en un documento "supuestamente consensual" que se garantice el pago de lo adeudado a través de este mecanismo.

\subsection{Indemnización en el seguro de desgravamen hipotecario}

Es menester tomar en cuenta para el desarrollo de este acápite, un punto muy importante ligado estrechamente al concepto de indemnización, que supone la producción o desencadenamiento del siniestro como tal, cual es el deber que tiene todo asegurado/prestatario de declarar el estado de riesgo, de manera inequívoca al momento de la contratación del Seguro de Vida o Póliza de Desgravamen Hipotecario.

Resulta tan importante este aspecto, que su correcta actuación delimitará que una entidad aseguradora obre objetiva y correctamente, al conocer todas las circunstancias que puedan influir en la valoración del riesgo que ésta asumirá; ya que de ser efectuada correctamente la entidad aseguradora procederá a liquidar el siniestro y a realizar el pago convenido en favor de la entidad financiera designada como beneficiario a título oneroso.

Para quienes trabajamos en este campo de seguros, esta situación podría equilibrar de cierta manera la mencionada desigualdad existente entre el asegurado o prestatario y la entidad aseguradora o entidad crediticia, ya que estos últimos deberán, bajo el principio de buena fe, confiar que la información proporcionada, permitirá en todo momento realizar una $20 \quad$ Ley $\mathrm{N}^{\circ} 26 / 2006$ de 17 de Julio. 
correcta apreciación del riesgo y finalmente decidir en función a las valoraciones y exámenes que realice, si o no el riesgo.

En todo caso, también puede entenderse que esta incorrecta, indebida o defectuosa declaración de todas maneras, afectará única y exclusivamente al asegurado o prestatario, pudiendo inclusive y de comprobarse su reticencia o falsa declaración, llegar a perder el derecho a que la compañía de seguros le indemnice.

Ahora bien, al respecto surge una interrogante: ¿qué sucede cuando la entidad aseguradora a través de su Formulario de Solicitud y Declaración de Salud, no formula correctamente las preguntas conducentes a establecer el estado real de salud de un futuro asegurado?, ¿será responsabilidad del asegurador asumir las consecuencias de esta situación, o por el contrario se tenderá a castigar al mismo? Por practica general, se tiene que toda legislación, tendera a proteger en todo momento al asegurado.

Sobre el particular, cabe mencionar que, en el caso boliviano, fue precisamente el ente fiscalizador (APS) quien, a través de un reclamo formulado por un interesado, solicitó a la entidad aseguradora un informe pormenorizado de la atención del siniestro, debiendo adjuntar la posición técnica y legal que fundamentó el rechazo, el mismo que tenia como premisa fundamental el incumplimiento de declarar en forma veraz y completa el estado de salud de la persona fallecida. Si bien se trataba de una póliza de seguro de vida, no hipotecaria, el fiscalizador determinó que el Formulario de Solicitud y Declaración de Salud, se encontraba incompleto en relación con la causal de rechazo esgrimida, razón por la cual dispuso que la entidad aseguradora realice el pago comprometido, cumpliendo con su obligación.

Ahora bien, si nos circunscribimos específicamente en el punto, se tendrá que toda póliza de Vida, en el presente caso de Desgravamen, deberá ser cancelada una vez producida la eventualidad prevista, fallecimiento o declarada la incapacidad de la persona ${ }^{21}$, en un plazo máximo de quince (15) días posteriores a la aceptación del siniestro.

21 La determinación de incapacidad total y permanente en Bolivia se realiza a través de médicos calificadores (auditores) debidamente registrados ante la APS, ya que el mercado de Pensiones también es regulado por la misma institución, quienes obran conforme la normativa del Seguro Social Obligatorio de Largo Plazo y el Manual especifico al caso. 
Sobre el punto específico se entiende, de acuerdo con la legislación boliviana que, presentados los requisitos solicitados coherente y oportunamente por la compañía o entidad aseguradora, ésta en el plazo máximo de treinta (30) días calendario desde su recepción, deberá manifestar la procedencia o improcedencia del caso. Cabe resaltar que la normativa cita el plazo de manera enunciativa, situación que no implica que la entidad aseguradora deba tomarse todo este tiempo para realizar el análisis respectivo.

En caso de que la aseguradora, incumpliera el plazo, el siniestro se tiene por aceptado con la obligación implícita de pagar dentro de los quince (15) días siguientes previstos y mencionados precedentemente, mecanismo con el cual se concluiría en si la función de la entidad aseguradora.

Ahora bien, hemos visto a lo largo de estos años que, si las entidades aseguradoras se limitaran a realizar el pago del saldo insoluto de la deuda, sin comunicar al asegurado en caso de tratarse de un caso de incapacidad total y permanente o bien a sus herederos legales en caso de tratarse de muerte, éstos no podrían requerir a la entidad financiera/ crediticia la devolución, si correspondiera, de las amortizaciones erogadas durante el plazo de tramitación del pago indemnizatorio.

Asimismo, y aunque en muchas circunstancias, sea considerado una actuación más allá de lo previsto en la norma, en Bolivia las entidades aseguradoras, solicitan a las entidades financieras puedan confirmar la liberación de las garantías hipotecarias, inmuebles, constituidas a la celebración del contrato de préstamo, situación que definitivamente permite el cumplimiento de la función social de esta clase de seguros.

Estos mecanismos, que no desgastan ni influyen en la relación comercial que pudiera tener la entidad financiera con la entidad aseguradora, permiten otorgar una adecuada protección a las personas, herederos del fallecido o al propio asegurado, declarado con incapacidad total o permanente.

Esto hace a la esencia del seguro y porque no decirlo del propio derecho, velando por el bien de las personas que a la larga y dado el nú- 
mero que constituyen, podría entenderse como un bien común tutelado, principio que prevalece en todo ordenamiento jurídico y que específicamente en materia de seguros, se refleja en la protección de la mutualidad de asegurados implicada, que justifica la tutela y contralor estatal de la actividad aseguradora.

\section{LEGISLACION COMPARADA}

No todas las legislaciones tienen prevista y menos aún otorgan la obligatoriedad mandataria a la contratación de una Póliza de Seguro de Vida o de Seguro de Desgravamen, tal cual refiere el caso de la Legislación Boliviana. En tal sentido, de la revisión realizada podemos señalar:

\subsection{España}

Como bien lo expusimos en el desarrollo del presente trabajo, la legislación española no refiere en ninguna norma específica, la obligatoriedad de contratar un Seguro de Vida para garantizar el Contrato de Préstamo. En la práctica se evidencia que son las propias entidades crediticias las que imponen esta obligación en el condicionado general de las "Pólizas de Seguros de Amortización de Préstamos".

La Ley de Seguros de España ${ }^{22}$, regula el Seguro de Personas, normativa dentro de la cual se evidencia que no existe imposición alguna que exija la contratación por parte del prestatario, de un seguro de vida.

Por su parte, en lo referido al contrato de préstamo con garantía hipotecario encontramos que la normativa ${ }^{23}$ aplicable dispone en su parte pertinente: “... el préstamo hipotecario tendrá que estar garantizado con un seguro de daños si el banco emite bonos, cédulas o participaciones sobre los préstamos que conceda"; refiriéndose única y exclusivamente a la protección del bien inmueble constituido en garantía, ante una eventual destrucción o desaparición.

22 Ley No. 50/1980 de 8 de Octubre a partir del Titulo IIl, Art. 80 y siguientes.

23 Ley Reguladora del Mercado Hipotecario No. 2/1981 de 25 de marzo y el Art. 10 del Real Decreto 716/2009, de 24 de abril. 


\subsection{Perú}

La legislación peruana ${ }^{24}$, al igual que la española, no contempla la contratación obligatoria del Seguro de Desgravamen Hipotecario según lo señala la Superintendencia de Banca y Seguros de este país. Sin embargo, debe anotarse que algunas empresas del Sistema Financiero exigen su contratación como condición necesaria para el otorgamiento de un crédito, resultando común la existencia de seguros de desgravamen en el caso de créditos hipotecarios, pero también en relación con créditos de consumo y de tarjetas de crédito.

\subsection{Colombia}

Colombia en relación a los créditos hipotecarios señala que, en tanto el prestatario no termine de pagar la totalidad de su deuda, debe la vivienda permanecer hipotecada a favor del banco, con la obligación reconocida por ley, de contratar un seguro obligatorio contra incendio y terremoto, ${ }^{25}$ que proteja el mismo.

Así también, reconoce como válidos todos aquellos seguros definidos internamente por las instituciones financieras, de manera particular el seguro de vida deudores, como garantía adicional conducente a que los prestatarios honren la deuda contraída; sin que este reconocimiento implique la obligatoriedad de su contratación y reconociendo en todo momento la libertad de contratación que tendrán éstos, pudiendo aceptar al proveedor contratado por la entidad financiera o bien adquiriendo el seguro en otra entidad aseguradora, siempre que reúna las características requeridas por la entidad crediticia o financiera, de conformidad a lo dispuesto por las reglas emitidas por Superintendencia Financiera de Colombia.

\subsection{Argentina}

La legislación argentina ${ }^{26}$, de manera específica y categórica, al igual

$24 \quad$ Ley del Contrato de Seguro Nº 29946 de 6 de noviembre 2012 - Perú.

25 Estatuto Orgánico del Sistema Financiero, Art. 101 - Colombia.

26 La Ley de Seguros No. 17.418 de 30 de agosto de 1967., Arts. 84 y 89 - Argentina. 
que la mayoría de los otros países, no contempla en su ordenamiento jurídico la obligación que tiene un prestatario de contratar un Seguro de Vida, cualquiera sea su modalidad, que tienda a respaldar la operación crediticia.

Si podemos mencionar, en relación al tratamiento que este país da a la figura de la Hipoteca - Prenda, a través de su Ley de Seguros disponiendo que, el acreedor debe notificar a la entidad aseguradora la existencia de una hipoteca o prenda y éste, salvo que se refiera a reparaciones del bien, no cancelara la indemnización sin dar aviso al acreedor, para que haga uso de su derecho de oposición en el plazo previsto.

Si las partes no llegasen a un buen entendimiento y de prosperar la oposición, la entidad aseguradora deberá realizar el depósito judicial de la indemnización, en tanto sea el juez quien resuelva la situación.

\subsection{Uruguay}

Finalmente, cabe referir que la legislación uruguaya respecto al Seguro de Desgravamen Hipotecario conocido como Seguro Colectivo de Vida Acreedor o de Saldo Deudor, por las similitudes que conllevan ambos, siguiendo la línea de la mayoría de los países Ibero-latinoamericanos, no dispone en su ordenamiento jurídico positivo, de ninguna regulación específica de carácter coercitivo.

En tal sentido, tanto la Ley de Relaciones de Consumo. Defensa del Consumidos $\mathrm{N}^{\circ} 17250$, de 11 de agosto de 2000, reglamentada por el Decreto $\mathrm{N}^{\circ} 244 / 00$ de 23 de agosto del mismo año, ni el Código de Comercio Uruguayo, en su sección III, Arts. 693 y sgtes. relativa a los Seguros de Vida, refieren el tema.

\section{CONCLUSIONES}

Del análisis realizado, se puede concluir que la reglamentación que pudiera surgir en relación a la obligatoriedad de contratación de una Póliza 
de Desgravamen Hipotecario, en los distintos países cualquiera fuera su denominación, y siempre que refiera una correcta constitución de garantía para quienes acceden a un Crédito Bancario, siempre que se resguarde su tratamiento, de tal forma que no sea contrario a los intereses y derechos del prestatario, permitirá de manera suficiente respaldar el patrimonio del mismo ante su fallecimiento o determinación de incapacidad total y permanente.

Bajo esta premisa, el presente trabajo de investigación propone entender, el carácter especialísimo que reviste la Póliza de Seguro de Vida bajo la cobertura Desgravamen Hipotecario tanto en la legislación boliviana, como el tratamiento que otorgan algunas legislaciones Ibero-latinoamericanas al respecto.

Indistintamente que el principio indemnizatorio, entendido como "dejar a la persona o a su familia, en la misma condición en que se encontraba antes de la ocurrencia de ese desafortunado evento denominado siniestro", no se cumpla bajo la modalidad de Seguros de Personas, en este tipo de seguros de Desgravamen Hipotecario podemos sí hablar de indemnización pues el asegurado no determina libremente el monto de suma asegurada que constituye la prestación a cargo del asegurador en un seguro de vida corriente, sino que la suma a indemnizar se relaciona al monto adeudado, con lo cual podemos decir que el seguro se torna similar a un seguro de daño, regido por el principio indemnizatorio. Esto significa que el asegurador deberá indemnizar el monto de saldo pendiente adeudado, ni más ni menos, salvo que existan contratadas otras coberturas adicionales.

Resulta pues de gran importancia, que toda persona, indistintamente de que pueda llegar a contratar o no una Póliza de Seguro de Desgravamen Hipotecario, logre entender el verdadero alcance y dimensión de su cobertura, de tal forma, que este conocimiento, conlleve un efecto multiplicador en todos los habitantes del hemisferio, garantizando la expansión y crecimiento de una verdadera "cultura de seguros" en la colectividad.

Este reto, acompañado de un correcto accionar de parte de las entidades aseguradoras en general, demostrará que indistintamente de que el seguro refiera la idea de un negocio en sí, remarque en todo momento la función social que en esencia lo acompaña, bajo la premisa de "cumplir lo con- 
venido".

\section{BIBLIOGRAFÍA}

- $\quad$ BATALLER GRAU, Juan y PEÑAS MOYANO, María Jesús; 2017. Un derecho del seguro más social y transparente.

- BRENES CORTES Josefa; Algunas cuestiones problemáticas derivadas de la concertación de seguros de vida vinculados a préstamos hipotecarios. Especial referencia al cumplimiento del deber de declaración de riesgo.

- BELLIDO CHAVEZ, Neil David 2017. El Seguro sus Bases Técnicas y Jurídicas. Enfoque al Mercado Boliviano.

- CAMPOY, Adilson; 2014. Contrato de Seguro de Vida.

- DEL REAL CORREA, E., 1955. El seguro de desgravamen hipotecario: aspecto social.

- FLORES VÁSQUEZ, E.L., 2017. Desprotección del cónyuge codeudor que no suscribió el contrato de seguro de desgravamen.

- SIGNORINO, Andrea; 2008. Los Seguros de Vida - Principales Aspectos Técnicos, Jurídicos y Comerciales.

- STIGLITZ, Rubén; 2010. Temas de derecho de seguros. Pontificia Universidad Javeriana.

- $\quad$ STIGLITZ, Rubén; 2016. Tratado de Seguros.

- PENAILILLO ARELLANO, G. and VIDAL DOMINGUEZ, I., 2006. El seguro de desgravamen hipotecario. 